\title{
Towards new weather and climate baselines for assessing weather and climate extremes, impacts and risks
}

\author{
Fiona Williamsona ${ }^{a^{*}}$, Rob Allan ${ }^{\mathrm{b}}$ and Rosanne D'Arrigo ${ }^{\mathrm{c}}$
}

a Asia Research Institute, National University of Singapore, 10 Kent Ridge Crescent, NUS, 11926o, Singapore

$b$ Climate Monitoring and Attribution Group, Met Office Hadley Centre, FitzRoy Road, Exeter, EX1 3PB, United Kingdom

c Lamont-Doherty Earth Observatory (LDEO), Columbia University, Tree Ring Lab, 61 Route 9W, PO Box 100o, Palisades NY 10964-80oo, United States of America

* Corresponding author. Email: f.williamson@uea.ac.uk

\section{ABSTRACT}

This project's goal has been to work with Southeast Asian institutions, archives, agencies and National Meteorological Services (NMS) to build capacities for improving and extending historical instrumental, documentary and palaeo databases of Southeast Asian weather and climate. The work plan comprised research into and cataloging sources of historical weather observations in archives and repositories globally and, the recovery (imaging and/or digitization) of the same where necessary and appropriate. These long datasets will contribute to the generation of high-quality, high-resolution historical dynamical weather reconstructions (reanalyzes). These will allow scientists and policymakers across the region to address weather/ climate extremes, impacts and risks in ways and over time span not previously possible. The project launched officially at a workshop involving scientists, historians, and archivists, brought together with the aim of opening a multi-disciplinary dialogue on historical records and their modern-day application. The project has been successful in establishing a regional arm of the international Atmospheric Circulation Reconstructions over the Earth (ACRE) initiative: ACRE SE Asia. ACRE SE Asia is unique, as no other body exists in the region with the same remit or aims.

\section{KEYWORDS}

Climate, data recovery, dynamical reconstructions, historic weather, reanalyses

DOI

https://dx.doi.org/10.30852/sb.2017.179

\section{DATES}

Received: 9 November 2016

Published (online): 22 November 2017

Published (PDF): 9 May 2018

\section{INTRODUCTION}

Initiatives to recover (sourcing, imaging, digitizing) historic datasets for generating more accurate longterm climate models have only gained momentum over the last decade, despite a long precedent of compelling arguments as to the value of historic weather observations (Le Roy Ladurie, 1972; Lamb, 1977). Although such work is relatively well established in Europe, the United States, China, and Japan; Southeast Asia currently has a dearth of data rescue initiatives with a long historical focus. The reasons behind this include a perception of the paucity of surviving data; the scattered nature of data due to shifts between colonial rule and independence and, later regime changes; a lack of local resources to develop data recovery projects. By way of example, the Southeast Asian Climate Assessment \& Dataset (SACA\&D) Digitisasi Data Historis (DiDaH) project, now completed, was limited by the fact that the bulk of observations recovered and digitized were in the post 1940s50 period (apart from Indonesia in the South East Asian region) and, their data rescue was directed at National Meteorological Service (NMS) records only, with generally a heavy focus on temperature and precipitation data. ACRE SEA has a wider scope, with a longer historical timeframe (especially with a pre 1940s-50s observations focus) and broader record collection base, using archives, libraries, and online sources across the region and internationally. In fact, the SACA\&D DiDaH project 
is linked closely to the main ACRE initiative, with one of its last meetings being paired with the inaugural ACRE SE Asia workshop (as noted below in Section 2). Another project, completed in 2011, was the Asian Precipitation - Highly-Resolved Observational Data Integration Towards Evaluation (APHRODITE) project. Again, the data rescue component was limited to only daily rainfall data and gridded precipitation from 1951 onwards. A follow-up project, APHRODITE Water Resources began in 2014, also with a contemporary data focus. Finally, it is worth mentioning that the Japan Climate Data Project (JCDP) data rescue efforts are closely linked to ACRE, to the extent that a new chapter of the ACRE project - ACRE Japan - has been initiated. See http://www.met-acre. net/chapters.htm for more information.

Thus, the primary goal of the ACRE SEA project has been to launch and establish ACRE SE Asia as an umbrella body to build both capabilities and capacities within SE Asian institutions, agencies and NMS to improve and extend historical instrumental, documentary and palaeo databases of SE Asian weather/climate (Williamson, 2016, 2015). ACRE SEA is, therefore, an integral part of wider ACRE initiative, the major international data rescue effort. These objectives have been achieved by: establishing linkages between ACRE SE Asia and institutions and individuals engaged in data recovery efforts regionally (such as similar ACRE activities with ACRE China - part of the UK-Chinese Climate Science for Service Partnership [CSSP China]); establishing a dialogue between disparate groups with an interest in historical weather records e.g. historians and archivists as well as scientists; and generating publicity for data recovery through an official project launch multi-disciplinary workshop.

Newly digitized historical SE Asian instrumental weather observations will contribute to the mass of global weather data being used by the latest generations of high-resolution historical global dynamical weather reanalyzes (especially EC FP7-funded European Reanalysis of the Global Climate System [ERA-CLIM2] and the ACRE-facilitated 20th Century Reanalysis Project [20CR]). These new data, global reanalyzes and downscaled products (such as via http://www.metoffice.gov. uk/precis) will provide scientists and policymakers across the region with baselines with which they will be able to address weather/climate extremes, impacts and risks in ways, and over time spans, not previously possible.

The project's main objectives were to:

1. Build capabilities and capacities within Southeast Asian institutions, agencies and NMS to improve and extend historical instrumental, documentary and palaeo databases of SE Asian weather/climate.

\section{HIGHLIGHTS}

» Two-day workshop bringing together regional NMS representatives, historians, policymakers and applications users

» Establishment of a regional arm of the international Atmospheric Circulation Reconstructions over the Earth (ACRE) initiative and, a steering group for the same

» The contribution of newly digitized weather observations to the International Surface Pressure Databank (ISPD).

» Establishment of a new network of regional linkages of organizations and individuals working on historic weather observations, data recovery, and analysis in the region

2. Contribute to the generation of high-quality, high-resolution historical dynamical weather reconstructions (reanalyzes).

3. Hold a workshop bringing together regional NMS representatives, historians, policymakers and applications users.

4. Establish a regional arm of the international Atmospheric Circulation Reconstructions over the Earth (ACRE) initiative: ACRE SE Asia.

\section{METHODOLOGY}

The APN CAPaBLE funded component of this project ran from August 2013 to December 2015. The first year focused on developing an inventory of currently known weather data across the Southeast Asian region. This involved first-hand primary research in regional NMS archives and national archives, alongside making contact with people and projects involved in data recovery in Asia. Year One culminated in a project launch in the form of a two-day workshop at the National University of Malaysia in Kuala Lumpur. This was held in conjunction with, and support from, the Royal Netherlands Meteorological Institute (KNMI) Indonesian Agency for Meteorology, Climatology, and Geophysics (BMKG) Digitisasi Data Historis (DiDaH) workshop in Indonesia. The workshops were arranged one week apart so that core partners were enabled to attend both events. This ensured a seamless and coherent engagement between them. Workshop participants discussed the availability and collaborative use of long-term regional weather/climate databases for detailed assessments of observed climate variability and change; future plans to image and digitize published data; created targets for new data recovery and available proxy climate/weather data for inter-comparisons, and explored links with regional applications and policymakers. The workshop also invited participation from 
historians and archivists in order to explore the potential of currently unused historic records for climate research (Allan, et al, 2015; Williamson, et al., 2015).

The second year saw a series of research meetings, archival and data recovery visits in Thailand, Vietnam, Singapore and the Republic of Korea to follow up on the workshop's outcomes; to catalogue and recover data where appropriate, and to discuss how newly recovered historical weather data could be fed seamlessly into ACRE-facilitated reanalyzes (Some examples of visualizations using ACRE-facilitated data can be accessed here). This connected with additional work undertaken by Williamson in Cambodia, Lao PDR, and the Philippines under ACRE China, part of CSSP China. Both funded years included a digitization component whereby pre-1950s weather data for the region were made available for the first time. The core project team comprised of Prof. Rosanne D'Arrigo, Lamont Doherty Earth Observatory (LDEO), Prof. Rob Allan United Kingdom Meteorological Office (UKMO), and Dr Fiona Williamson, National University of Singapore (NUS).

\section{RESULTS AND DISCUSSION}

Southeast Asian data uncovered during this project will be, where appropriate, assimilated into freely available $4 \mathrm{D}$ historical global dynamical weather reconstruc- tions (reanalyzes) spanning the last $200+$ years. A comparison of $20 \mathrm{CR}$ with three other reanalyzes is available here. Dynamical downscaling by Providing Regional Climates for Impacts Studies (PRECIS) team models will then take the reanalyzes output down to finer resolution ( $25 \mathrm{~km}$ to $100 \mathrm{~m}$ ), for use by the climate science community, wide-ranging climate applications and services, policymakers, planners, environmental managers, educational and public needs across the SE Asian region (see ACRE structure ). All of the above are considered necessary to provide the basis for the climate applications community, decision and policymakers across the region to access and utilize the new high-resolution databases, reanalysis outputs, and dynamical downscaling products.

Throughout the project, we have also been undertaking on-going work with DiDaH on bringing together historical instrumental weather observations with currently held contemporary data for the region in the SACA\&D database. One benefit from this is that it raises the potential to extend the bevy of Expert Team on Climate Change Detection Indices (ETCCDI)-derived indices to much longer timeframes, making them even more valuable to the climatic variability, change, and applications research communities. At the same time, we have been creating our own database of sources for the

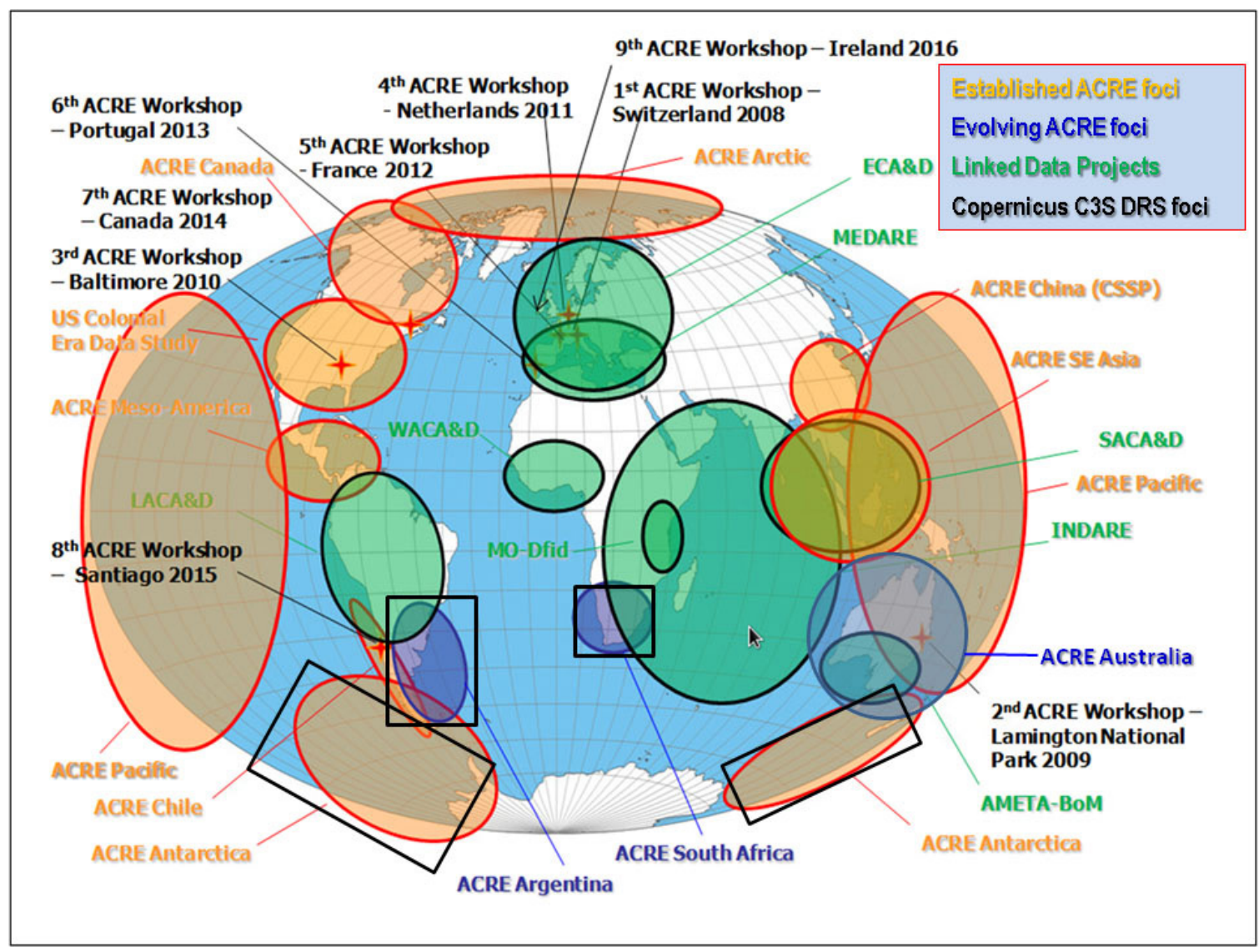

FIGURE 1. ACREs global reach. 
region. This includes sources located in the region itself and data held externally either at European archives or by projects partners, e.g. Japan Agency for MarineEarth Science and Technology (JAMSTEC), JCDP, the China Meteorological Agency (CMA) and the new ACRE Australia focus (Ashcroft et al., 2016). This has meant a process of uniting scattered data which in turn can be shared with original host countries-especially ex-colonial countries. As well as revealing gaps in knowledge and areas on which future research should be focused, the database has also revealed duplication, important in itself because this highlights the value of compiling such a database.

ACRE is the dominant initiative in climate data science as far as having a principal component that is both undertaking and facilitating the rescue of historical weather and climate data, and thus the major server of long surface weather data records to all reanalyzes. Figure 1 shows ACREs global reach currently, and its linkages to other data rescue activities and the new EU Copernicus Climate Change Service (C3S) Data Rescue Service (DRS).

ACRE SE Asia is now an integral part of this global strategy, and efforts to build an international integrated database of surface meteorological observations (Thorne et al., 2017). Since submitting the original APN CAPaBLE proposal, the International ACRE Initiative has become an even more integral part of the expanding and enhanced (Met Office [MO]-University of Southern Queensland [USO]) Collaboration Agreement (a partner in ACRE SE Asia). Thus, ongoing activity and project development by USQ already underway in SE Asia, linking climate analysis and agricultural production modelling, will require outputs and outcomes from the new ACRE SE Asia foci to be sustained. These activities will utilize and expand the data recovery and associated activities across SE Asia that is already an integral component of this USQ (soon to be MO-USO) activity. ACRE SE Asia and MO-USQ will provide the basis to underpin ongoing wider climate applications, policy and decision support, delivery and usage of data and reanalysis outputs across the region.

ACRE SE Asia is also now being supported through its linkages to the ACRE China component of the Climate Science for Service Partnership China (CSSP) - a bilateral partnership between the UK Met Office, the CMA, the Institute of Atmospheric Physics (IAP) at the Chinese Academy of Sciences, and other key institutes within China and the UK. This is a 3-year project from 20152018, during which time adjunct research work will be undertaken on building a database of sources Southeast Asian historical weather observations and work will be extended to include Taiwan, Macau, Myanmar, and the Philippines. It is anticipated that information currently stored in European repositories can be reunited with ex-colonial countries where applicable, and more data sharing initiatives can be enacted. There was a major workshop held in Beijing in August 2016 under the auspices of ACRE China, in which ACRE SE Asia collaborators attended and presented (Williamson et al., 2016) and another in Hong Kong in March 2017. In addition, monies are being sought to enable specific data recovery projects for early 2oth century hard copy meteorological observations (imaging and digitization) held in the NMS in Lao PDR and Cambodia. Williamson will also continue research into sources of historical data for the region, by individual research, and by working with regional partners, to facilitate this. One important area of work is raising funds for two recovery projects, to rescue hard copy data currently held in storage at the Department of Meteorology and Hydrology (DMH), Vientiane, Lao PDR and Ministry of Water Resources and Hydrology (MOWRAM), Phnom Penh, Cambodia. In both cases, neither country currently has the resources or capabilities to recover this documentation and vital data stands to be lost without a recovery project.

In terms of moving forward, this research contributes weight to a compelling argument for the value of a global, publicly-accessible, integrated database and portal for historical weather data. The World Meteorological Organization (WMO) International Data Rescue (I-DARE), the European Commission Seventh Framework Program (EU FP7) European Reanalysis of the Global Climate System (ERA_CLIM2), C3S DRS and Indian Ocean Data Rescue (INDARE) projects are prime examples of efforts to address such needs, but what is required is a truly international 'one-stop' database and portal for such material (Thorne et al., 2017). This will be a major topic discussed during the second half of the 9th annual ACRE Workshop in Ireland in June 2016. The ACRE SE Asia project has also highlighted the importance of open data sharing policies to which not all countries subscribe. This current deficiency leads to gaps where data does exist but is not allowed to be shared. ACRE is strongly placed to work with the international data/data rescue community on this issue.

More work needs also to be undertaken as direct and indirect consequences of this two-year project. Directly, it would be useful to consider, or to take part in, initiatives to encourage open data sharing regionally. Indirectly, the project has shown that a great deal of data does exist for the region that still needs to be collated. The project needs to be extended across Southeast Asia and, in particular, European archives and NMS repositories need to be mined for information. The project recommends an extension to Myanmar, Lao PDR, Cambodia, and the Philippines. A critical step forward would also be to seek 
funds for large recovery projects on new source data.

\section{CONCLUSION}

This two-year project has achieved the following objectives. To:

1. Build both capabilities and capacities within Southeast Asian institutions, agencies and NMS to improve and extend historical instrumental, documentary and palaeo databases of SE Asian weather/climate.

2. Contribute to the generation of high-quality, high-resolution historical dynamical weather reconstructions (reanalyzes).

3. To hold a workshop bringing together regional Meteorological Department representatives, historians, policymakers and applications users. This workshop was successfully held in May 2014 at the National University of Malaysia. It brought together people from disparate fields - across the humanities and sciences - to frame a dialogue on historical data sources, their recovery, and usage in addressing modern challenges.

4. To establish a regional arm of the international Atmospheric Circulation Reconstructions over the Earth (ACRE) initiative: ACRE SE Asia.

The outcomes and outputs of this project will address the needs of decision-makers and users of climate services in the region and, globally. It will contribute to the ability of these less developed countries to develop and understand their own data recovery capacities, preserve an invaluable resource for the global climate user and research community, and add to the knowledge of a region that is particularly sensitive to climate risks now, and in the future. ACRE is currently investigating sources of funding to enable continuing this important project.

\section{ACKNOWLEDGEMENTS}

Juerg Leuterbacher, University of Giessen and Jun Matsumoto, Tokyo Metropolitan University for facilitating digitization work on behalf of ACRE SE Asia.

\section{REFERENCES}

Allan, R., Endfield, G., Damodaran, V., Adamson, G., Hannaford, M., Carroll, F., ... \& Hendy, E. (2016). Toward integrated historical climate research: the example of Atmospheric Circulation Reconstructions over the Earth. Wiley Interdisciplinary Reviews: Climate Change, 7(2), 164-174. DOI: https://doi.org/10.1002/ wcc.379

Ashcroft, L., Allan, R., Bridgman, H., Gergis, J., Pudmenzky, C., \& Thornton, K. (2016). Current climate data rescue activities in Australia. Advances in Atmospheric Sciences, 33(12), 1323. DOI: https://doi. org/10.1007/s00376-016-6189-5
Lamb, H. H. (1977). Climate: Present, Past and Future. vol. 2: Climatic History and the Future, $835 \mathrm{pp}$. Methuen \& Co, London.

Ladurie, E. L. R. (1971). Times of feast, times of famine: a history of climate since the year 1000. Doubleday.

Thorne, P. W., Allan, R. J., Ashcroft, L., Brohan, P., Dunn, R. H., Menne, M. J., ... \& Bronnimann, S. (2017). Toward an Integrated Set of Surface Meteorological Observations for Climate Science and Applications. Bulletin of the American Meteorological Society, 98(12), 2689-2702. DOI: https://doi.org/10.1175/ BAMS-D-16-0165.1

Williamson, F. (2016). Cross-disciplinary working in the sciences and humanities: Historical data rescue activities in Southeast Asia and beyond. Geoscience Letters, 3(1), 31. DOI: https://doi.org/10.1186/ s40562-016-0062-3

Williamson, F., Allan, R., Switzer, A. D., Chan, J. C., Wasson, R. J., D'Arrigo, R., \& Gartner, R. (2015a). New directions in hydro-climatic histories: observational data recovery, proxy records and the atmospheric circulation reconstructions over the earth (ACRE) initiative in Southeast Asia. Geoscience Letters, 2(1), 2. DOI: https://doi.org/10.1186/s40562-015-0018-z

Williamson, F. (2015b). Weathering the empire: meteorological research in the early British straits settlements. The British Journal for the History of Science, 48(3), 475-492.

Williamson, F., Ren, G., \& Allan, R. (2017). The Atmospheric Circulation Reconstructions over the Earth (ACRE) initiative ACRE China workshop: Recovery, digitization, and analysis of pre-mid-twentieth century climate observational data in East Asia workshop on 23-24 August, Beijing, China. Earth and Space Science, 4(1), 40-43. DOI: https://doi. org/10.1002/2016EA000215. 